\title{
Stability assessment of the chemical composition of the treated mining water used to replenish the cooling circuit in Jaworzno III Power Plant - Power Plant II
}

\author{
Marcin Karpiński ${ }^{1,{ }^{*}}$, Ewa Kmiecik $^{1}$ \\ ${ }^{1}$ AGH University of Science and Technology, Faculty of Geology, Geophysics and Environment \\ Protection, Al. Mickiewicza 30, 30-059 Kraków, Poland
}

\begin{abstract}
In Poland, electricity is still produced mainly in conventional power plants where fuel and water are materials necessary to generate the electricity. Even in modern power plants operating according to the principles of the sustainable development, this involves a high intake of water and considerable production of wastewater. This, in turn, necessitates the application of some technological solutions aimed at limiting the negative impact on the environment. The Jaworzno III Power Plant Power Plant II is located in Jaworzno, Silesian Province, Poland. In order to minimise the negative impact on the surface water, the plant replenishes the cooling circuit with the mining water obtained from the closed-down Jan Kanty mine. The paper presents a stability assessment of the chemical composition of the treated mining water used to replenish the cooling circuit based on the data from 2007-2017.
\end{abstract}

\section{Introduction}

Production of electricity in Poland is carried out mainly in conventional power plants than e.g. in hydropower plants [1], so the necessary resources include fuel and water. Generation of electricity in conventional power plants is carried out in a three-stage energy conversion process. The chemical energy stored in fuel and released in the combustion process in the boiler is converted into steam thermal energy. Subsequently, superheated steam is used to move the blades of the turbine driving the generator in which mechanical energy becomes converted into electricity [2]. Additionally, certain part of energy carried by steam may be used for heating of water in district heating networks.

Electricity generation requires large quantity of water, however in modern plants, it is carried out in accordance with the sustainable development principle in the manner that is least detrimental to the environment. Due to the high purity requirements for water used in process circuits and for the protection of the quality of surface waters that are often a source of drinking water, power plants use their own water treatment plants and wastewater treat-

\footnotetext{
*Corresponding author: karpinski@agh.edu.pl
} 
ment plants. Some amount of water is reused to supplement the losses in the circuits with lower quality requirements $[3,4]$.

\section{Jaworzno III Power Plant - Power Plant II characterisation}

The Jaworzno III - Power Plant II operated by TAURON Wytwarzanie S.A. is located in south-western part of Jaworzno, ca. $2.5 \mathrm{~km}$ away from Przemsza river. In the period between 1995 and 2000, due to increased environmental protection requirements, it underwent major upgrade and was repurposed as a municipal combined heat and power plant [5]. The maximum electric output of the Power Plant II is 190 MWe, while the maximum thermal capacity is $318 \mathrm{MWt}$. The power plant is equipped with three fluidized bed boilers: two fired with hard coal and coal sludge and one fired with biomass. All boilers are coupled with district heating and condensing turbines which are equipped with single-stage $\mathrm{DH}$ exchangers [6].

\section{Water circuits}

There are three main water circuits in the power plant: water/steam circuit (boiler circuit), cooling circuit and district heating circuit (fig. 1) [7].

The power plant operates a closed cooling circulation system with a maximum capacity of $9720 \mathrm{~m}^{3} / \mathrm{h}$. The water taken up from the cooling water channel is pumped to the condenser where it is heated. Next, the water is pumped to the cooling tower and, after cooling, it is recycled to the cooling water channel. Evaporation of water in the natural draft cooling tower results in condensation of the circulating liquid [8]. The entire condensed cooling water must be removed in the form of blowdown from the cooling circuit and replenished with treated water [7].

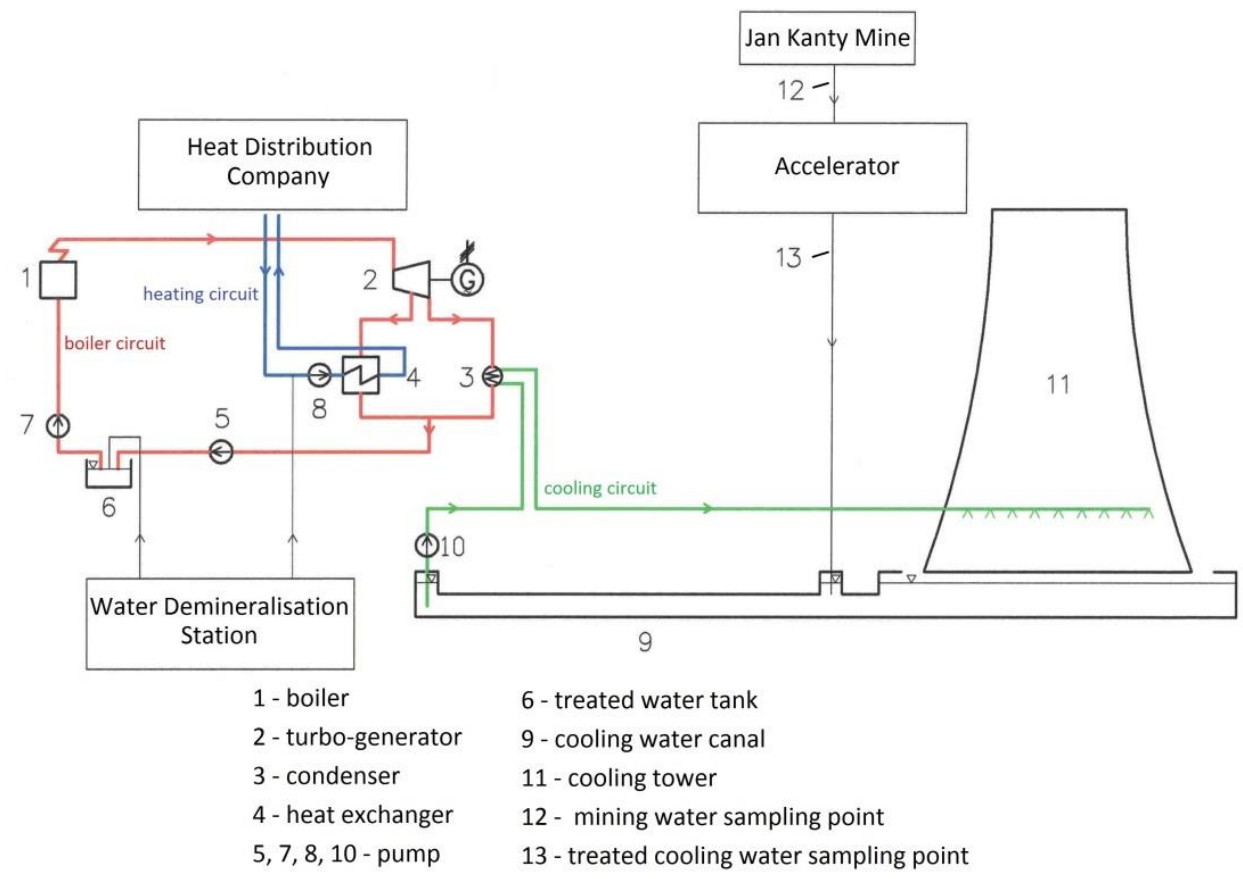

Fig. 1. Water circuits in the power plant Jaworzno II [7]. 


\section{Water sources}

Apart from fuel, water is the basic material used in the process of electric and thermal power generation from non-renewable sources. Consumption of water in conventional power plants with open or closed cooling water system is between 1.7 and $8.0 \mathrm{~m}^{3} / \mathrm{MWe}$ [9]. An average-sized conventional power plant consumes several million cubic meters of water, the majority of which is used in the cooling processes [2].

The plants utilizing natural water resources are obliged to abide by the water protection laws. Due to increasing prices of water intake and use of the environment, the regulations enforce rational water management. The environment protection is especially one of the biggest issues in the Silesia province. The heavy industry located in this area has an effect on ground and surface water [10]. In order to reduce costs and negative environmental impact, the Power Plant II uses, for water production and cooling circuit replenishment, the mine water from the defunct Jan Kanty Mine held by Spółka Restrukturyzacji Kopalń and surface water from Biała Przemsza river in the total amount of 4,600,000 $\mathrm{m}^{3} /$ year [11]. A stationary drainage system is maintained at the Jan Kanty Mine, while the inflow of mine water amounts to ca. $30 \mathrm{~m}^{3} /$ minute [12]. Drainage of this defunct mine results from the necessary protection against flooding of the TAURON Sobieski Mining Plant [13].

\section{Cooling water treatment}

The water temperature for the needs of the cooling circuit should be low. Additionally, it must not contain chemicals causing scale to deposit on heating surfaces and should be noncorrosive towards materials from which the components of the circuit are made. The water used to supplement the losses in the cooling circuit is prepared in the coagulation and decarbonisation processes occurring in accelerators [14]. In the process of water preparation for cooling circuit purposes, it is very important to bring water to carbonate calcium equilibrium. This reduces water's aggressive properties and prevents precipitation of calcium carbonate [15].

The raw water originates from the Jan Kanty mine, from a carboniferous aquifer and is classified as fresh and semi-fresh water. It is characterized by low mineral content of approx. $1000-1200 \mathrm{mg} / \mathrm{l}$, concentration of sulphate of approx. $310 \mathrm{mg} / \mathrm{l}$ and chloride of approx. $115 \mathrm{mg} / 1$ [16]. The presence of these ions adversely affects the operation of power engineering equipment. They promote the corrosive character of water towards metals and concrete. Due to high concentration of sulphates and chlorides which are not removed in the carbonate removal process, the water in the cooling circuit requires continuous treatment. The resulting blowdown is pumped to the power plant's wastewater treatment station and, subsequently, in accordance with the integrated permit, it is discharged to Przemsza river $[17,18]$.

\section{Methodology}

The testing of raw and accelerator-treated mine water chemical composition was carried out on a monthly basis in the period between 2007-2017. The samples were collected by the personnel of the Power Plant II in accordance with plant's quality system procedures (PN-EN ISO 5667-13:2004, 2011). Sampling points are shown on the fig. 1.

The water was subsequently analyzed by the laboratory of TAURON Wytwarzanie (PCA accreditation certificate No. AB 688). A maximum of 15 parameters were measured in the samples, while this paper concerns ions whose increased concentration is typical for 
mine water: sulphate $\left(\mathrm{SO}_{4}{ }^{2-}\right)$ and chloride $\left(\mathrm{Cl}^{-}\right)$ions as well as $\mathrm{pH}$ and electrical conductivity (EC).

Sulphate concentration was determined by turbidimetry method, chloride concentration was determined by Mohr method (PN-ISO 9297: 1994), the pH and EC values was determined by potentiometric (PN-EN ISO 10523: 2012) and conductometric (PN-EN 27888: 1999) methods respectively $[15,19]$. Trend analysis methodology is presented e.g. in [20].

\section{Data analysis}

In order to evaluate raw and treated water chemical composition stability, the results of 114 analyses from the period between 2007 and 2017 were used. In March and April 2014 as well as August, October, November and December 2016 the power plant did not use mine water and its composition was not analyzed. Table 1 presents basic descriptive statistics for the entire data set.

Table 1. Basic descriptive statistics for the EC, $\mathrm{pH}$, chloride and sulphate ions concentration in mining water $(\mathrm{M})$ and treated water $(\mathrm{T})$.

\begin{tabular}{|c|c|c|c|c|c|c|c|c|}
\hline \multirow{2}{*}{$\begin{array}{c}\text { The value of } \\
\text { statistics }\end{array}$} & \multicolumn{2}{|c|}{$\mathbf{E C}[\boldsymbol{\mu S} / \mathbf{c m}]$} & \multicolumn{2}{c|}{$\mathbf{p H}[-]$} & \multicolumn{2}{c|}{ Chlorides [mg/l] } & \multicolumn{2}{c|}{ Sulphates [mg/l] } \\
\cline { 2 - 9 } & $\mathbf{M}$ & $\mathbf{T}$ & $\mathbf{M}$ & $\mathbf{T}$ & $\mathbf{M}$ & $\mathbf{T}$ & $\mathbf{M}$ & $\mathbf{T}$ \\
\hline Mean & 1147 & 1351 & 9.55 & 7.55 & 141.3 & 141.7 & 374.5 & 383.6 \\
\hline Std. deviation & 85 & 39 & 0.47 & 0.20 & 16.5 & 4.0 & 51.5 & 41.4 \\
\hline Minimum & 663 & 1173 & 8.20 & 7.13 & 46.1 & 128.0 & 243.0 & 297.0 \\
\hline Maximum & 1391 & 1444 & 11.00 & 8.07 & 184.6 & 156.2 & 495.0 & 464.0 \\
\hline Range & 728 & 271 & 2.80 & 0.94 & 138.5 & 28.2 & 252.0 & 167.0 \\
\hline
\end{tabular}

The analysis of sequence plots for EC (fig. 2), pH (fig. 3), chloride (fig. 4) and sulphate (fig. 5) ions concentration in raw mine water shows that there are no statistically significant monotonous trends. It means that raw mine water is characterized by stable chemical composition in respect of these parameters. The sulphate concentration chart (fig. 5) over time reveals three groups of results related to changes in the drainage system at the Jan Kanty Mine [21] and reduction of pyrite oxidation processes [22, 23].

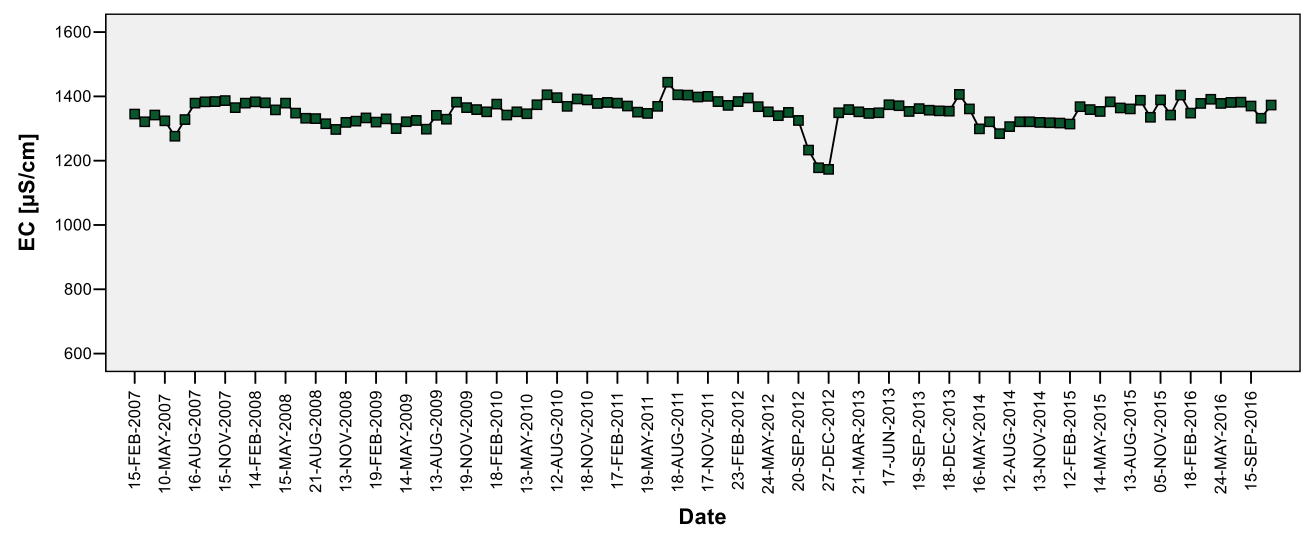

Fig. 2. Conductivity changes in mine (M) water in 2007-2017. 


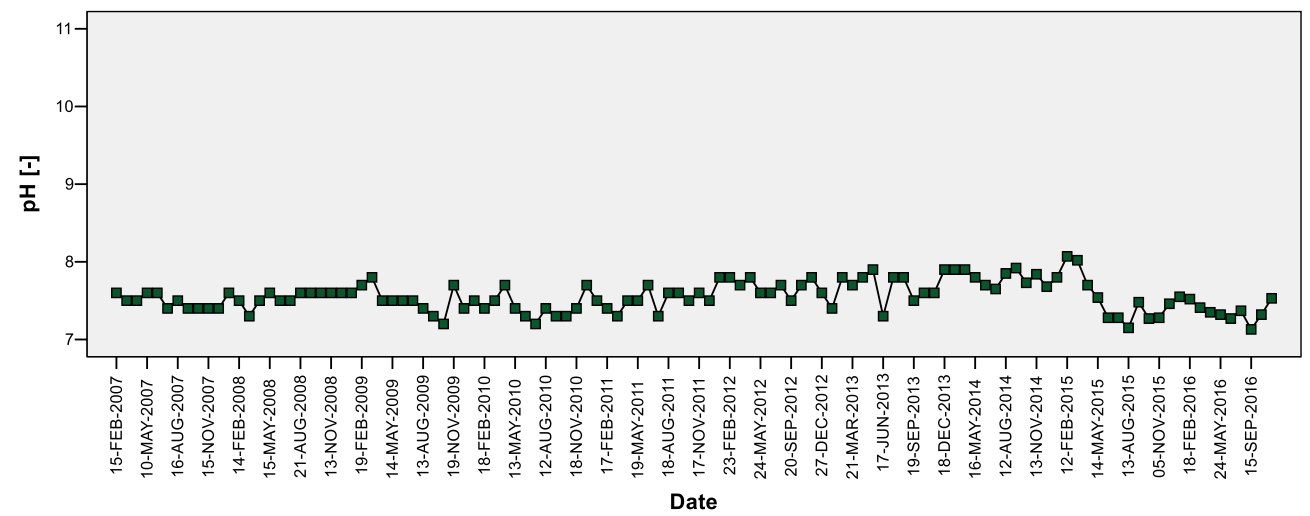

Fig. 3. pH changes in mine (M) water in 2007-2017.

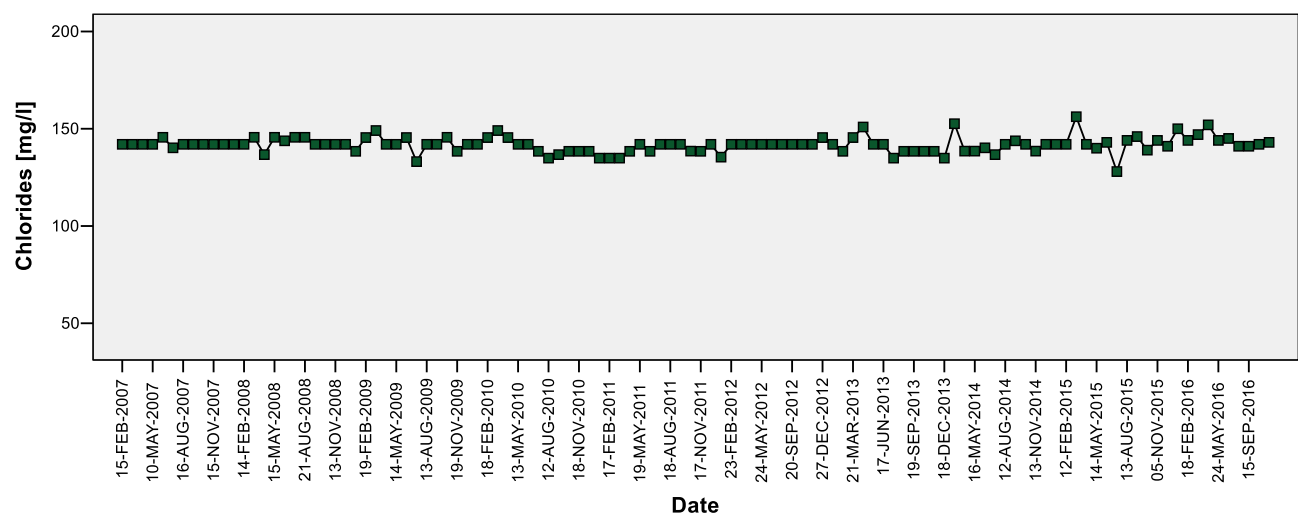

Fig. 4. Fluctuation of chlorides concentration in mine (M) water in 2007-2017.

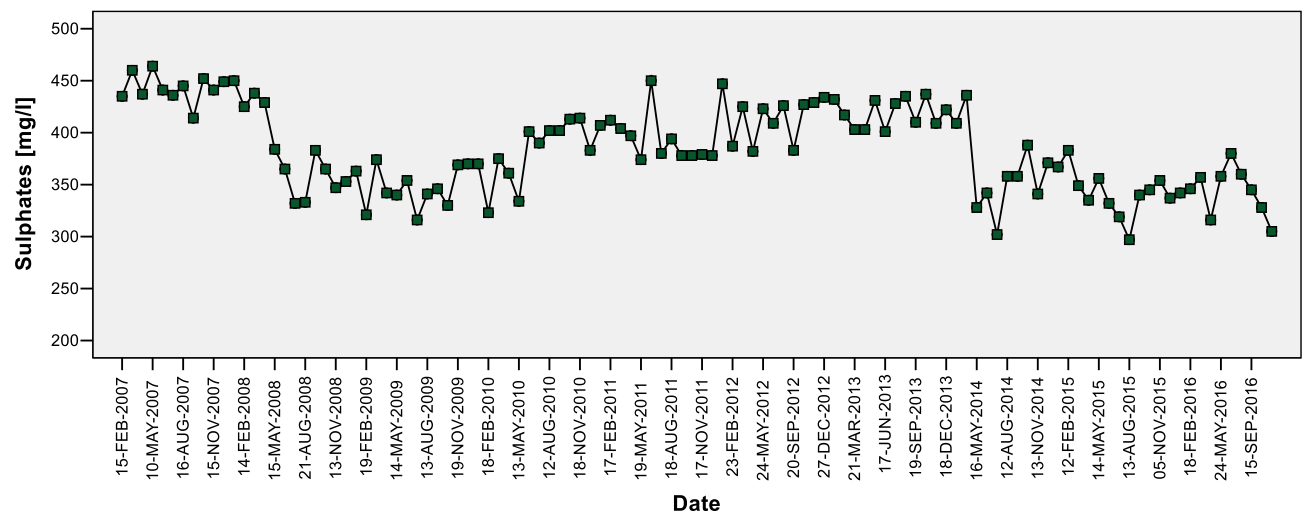

Fig. 5. Fluctuation of sulphate concentration in mine (M) water in 2007-2017.

The analysis of sequence plots for EC (fig. 6), $\mathrm{pH}$ (fig. 7), concentration of chloride (fig. 8) and sulphate (fig. 9) ions concentration in treated water (used to make-up losses in the cooling circuit) shows also that there are no statistically significant monotonous trends. It means that treated water is also characterized by relatively stable chemical composition in respect of these parameters. The parameter variability charts over time show only single results with reduced EC, $\mathrm{pH}$ and $\mathrm{Cl}^{-}$and $\mathrm{SO}_{4}{ }^{2-}$ concentrations. During months in which the analyses were carried out, a mix of mine water and water sourced from Biała Przemsza river was used to make-up the losses in the cooling circuit that are characterized by clearly 
better chemical parameters: lower electrical conductivity and concentration of chloride and sulphate ions.

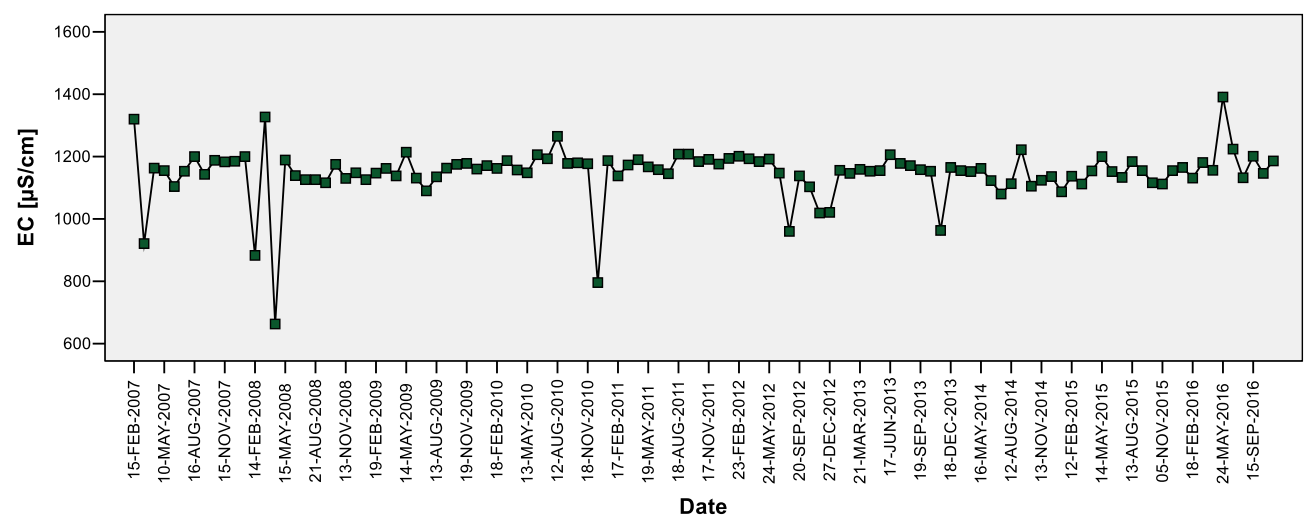

Fig. 6. Conductivity changes in treated (T) water in 2007-2017.

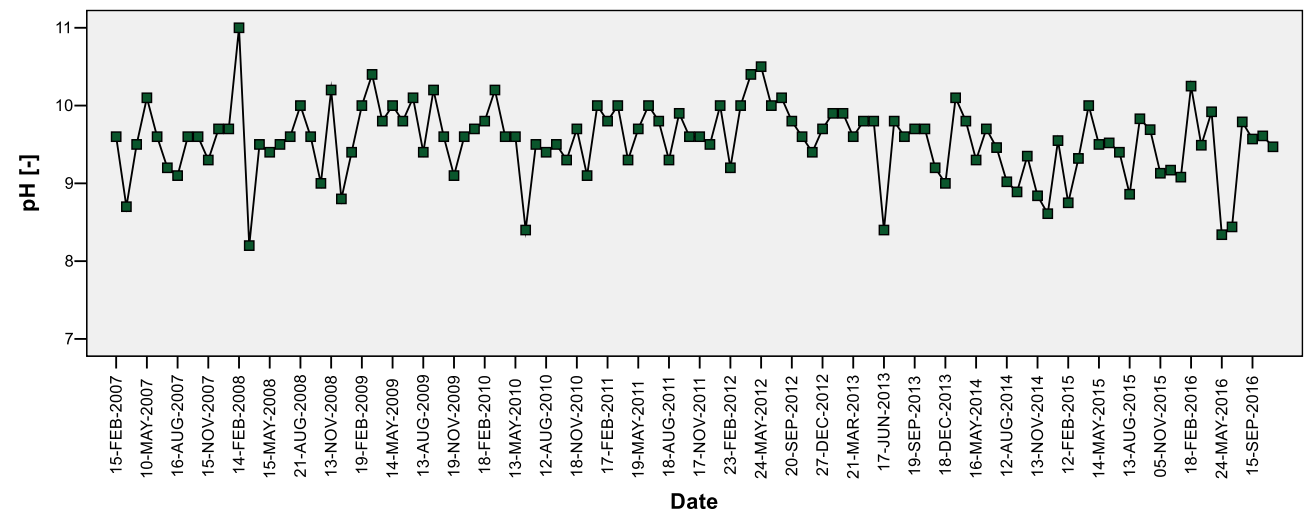

Fig. 7. pH changes in treated (T) water in 2007-2017.

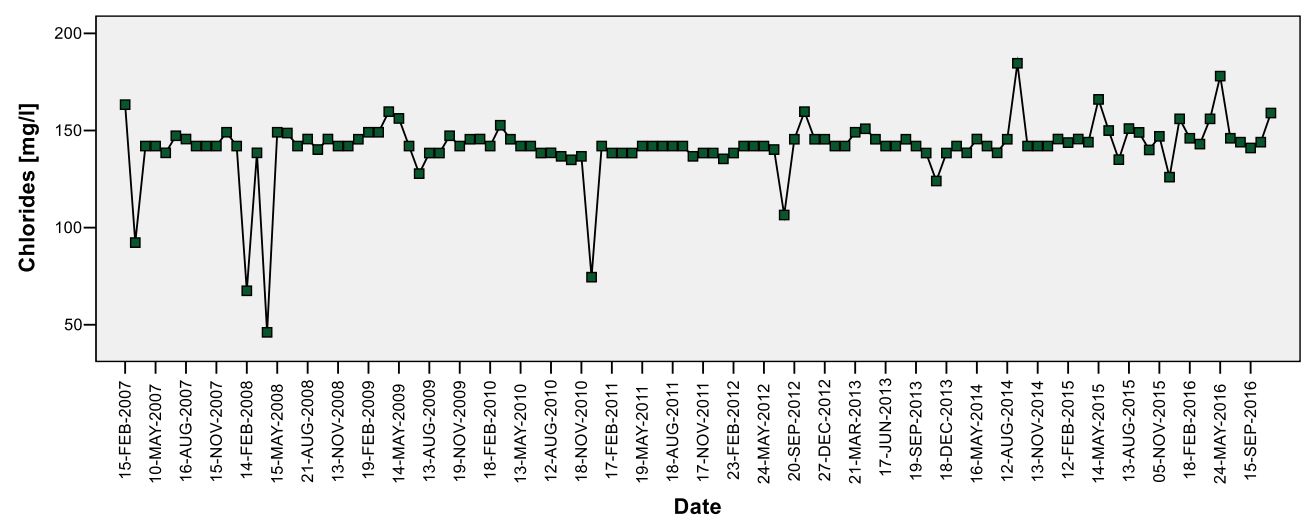

Fig. 8. Fluctuation of chlorides concentration in treated (T) water in 2007-2017. 


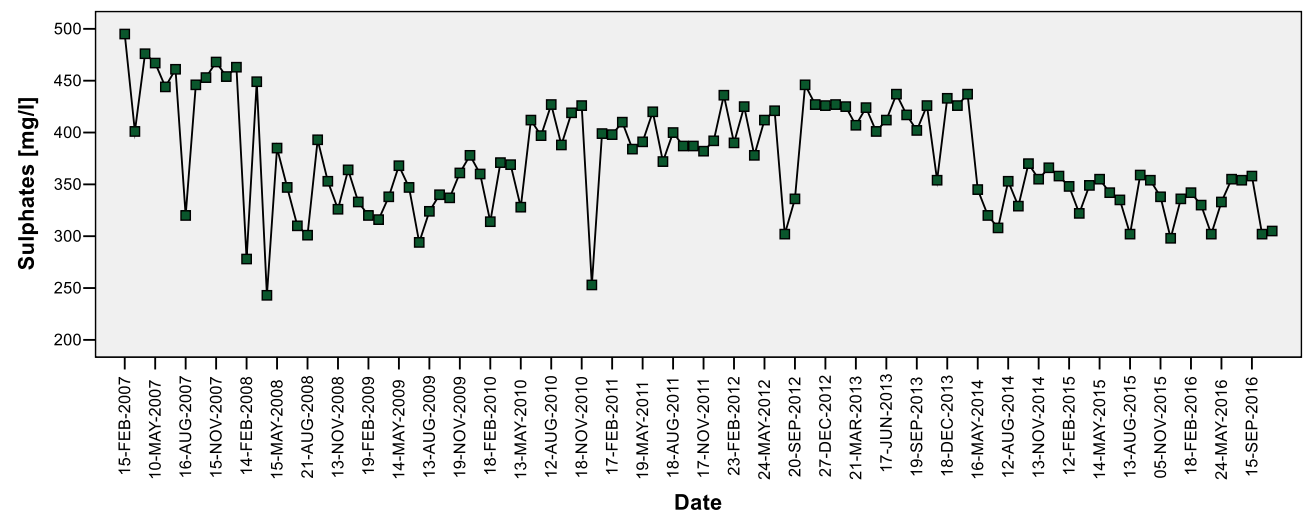

Fig. 9. Fluctuation of sulphate concentration in treated (T) water in 2007-2017.

\section{Summary}

This paper presents the evaluation of stability of chemical composition of mine water used at the Power Plant II. The analysis was carried out for $\mathrm{Cl}^{-}$and $\mathrm{SO}_{4}{ }^{2-}$ ions as well as electrical conductivity and $\mathrm{pH}$. The analysis of chemical composition changes in time did not reveal any statistically significant trends. For sulphate ions in raw water, three groups of results were found that may be related to drainage activities at the Jan Kanty mine. For treated water analyses, the results deviating from the average are related to treatment of mine water and water taken up from Przemsza river simultaneously. This confirms that mine water and treated water are characterized by stable chemical composition.

Mine water typically shows increased chloride and sulphate concentrations as compared to surface water. Therefore, they also show considerable corrosive activity. At the same time, they have relatively stable chemical composition depending mainly on the physical and chemical properties of the geological location. Its chemical composition is not affected by a number of factors which are of importance for surface water, e.g. current season, thawing, rainfall or presence of contamination from wastewater [15]. Relative chemical stability of mine water allows for easier determination of chemical dosage during water treatment.

The authors would like to thank branch managers Matgorzata Sztyrak and Mirostaw Żbik (TAURON Wytwarzanie S.A.) for providing data for the purposes of this paper.

This work has also been conducted under AGH-UST statutory research grant No. 11.11.140.797.

\section{References}

1. A. Operacz, B. Tomaszewska, Environ. Sci. Pollut. 23, 19, 18953-18959 (2016)

2. D. Sąkol-Sikora, Energet. Ciepl. i Zaw. 9 (2011)

3. J.R. Rak, B. Kucharski, Environ. Prot. Eng. 35, 2, 15-21 (2009)

4. D. Sąkol-Sikora, Joint Meeting of Water Management Councils of the Water Regions: Little Vistula and Upper Oder and the Presidencies of the Standing Committee for the Participation of the Society Conf Proc, Toszek (2009)

5. http://www.tauron-wytwarzanie.pl/oddzialy/jaworznoiii/Strony/opis.aspx (15.03.2017) 
6. Environmental Impact Review - Jaworzno III Power Plant, Sozoprojekt (2009) (in Polish)

7. Operating Instructions of turbogenerators, Nr CKI 2005/320/Er (mat. TAURON) (in Polish)

8. R. Laskowski, A. Smyk, J. Lewandowski, A. Rusowicz, A. Grzebielec, Energy 107, 725-733 (2016)

9. T. Jamrocha, VIII Discussion Forum Diagnostics and chemistry for power industry Conf. Proc. Szczyrk, 161-171 (2011)

10. T. Suponik, Environ. Prot. Eng. 41, 1, 15-27 (2015)

11. Jaworzno III Power Plant - Water budget (mat. TAURON) (2015)

12. A. Czapnik, A. Jasińska, E. Janson. Biuletyn PIG. 436, 55-60 (2009)

13. J. Siemieniec, J. Wodecki, M. Gałęziowski, Monograph SRK (2005) (in Polish)

14. A. Puszkarewicz, J. Kaleta, A. Piech, Environ. Prot. Eng. 35, 4, 41-48 (2009)

15. E. Sierakowski, J. Mrożek, Control of water and steam in power industry (Wyd. Energopom. Elektr., 1998) (in Polish)

16. A. Olszówka, Environmental Impact Review of starting production in the area closed down mine Jan Kanty, EC Katowickie Przedsiębiorstwo Geologiczne (2012) (in Polish)

17. Operating instructions for decarbonisation and water coagulation stations, $\mathrm{Nr} \mathrm{CKI}$ 2005/295/Er (mat. TAURON) (in Polish)

18. Integrated permits for fuel combustion installation Jaworzno III Power Plant in Jaworzno, Nr 360/OS/2012 (in Polish)

19. http://www.pca.gov.pl/akredytowane-podmioty/akredytacje-aktywne/laboratoriabadawcze/AB\%20688,plik.html (20.03.2017)

20. E. Kmiecik, S. Stefaniak, J. Szczepanska, I. Twardowska, Proc. Of Spie. 5586, 126-135 (2004)

21. P. Bukowski, I. Augustyniak, SGEM2013 Conf. Proc. 2, 25-32 (2013)

22. R.J. Bowell, IMWA Symp. Proc. 2, 75-91 (2004)

23. K. Labus, S. Skoczynska, Geol. Q 57, 3, 561-566 (2013) 